\title{
Co-production in action: perceiving power in the organisational dimensions of a global biodiversity expert process
}

\author{
Jasper Montana ${ }^{1,2}$ (D) \\ Received: 19 June 2018 / Accepted: 15 February 2019 / Published online: 13 March 2019 \\ (C) The Author(s) 2019
}

\begin{abstract}
Opening up knowledge-action systems to a wider range of disciplinary and societal actors is considered to be a necessary step in achieving transformative change for sustainability. In science for sustainability, there is a growing body of experience and literature of putting this 'co-production' into action. However, there is an opportunity to strengthen the application of analytical resources for more explicitly recognising and accounting for the power relations embedded in these initiatives. This paper deploys social theory from science and technology studies to develop an approach to perceive power relations between the participants, processes and products of co-production. This necessitates paying attention to the multiple and distributed organisational spaces where co-production takes place to discern: who participates; who (and what) is represented; how deliberations are structured; and how outcomes are circulated. This paper shows that these organisational dimensions of participation, representation, deliberation, and circulation not only give structure to co-productive forums, but can also define the power relations between their participants, processes and products. The paper then illustrates the applicability of this approach using the case of a current global expert process for biodiversity: The Intergovernmental Platform on Biodiversity and Ecosystem Services (IPBES). This case study offers insights on the challenges and opportunities for designing and evaluating co-production initiatives for sustainability.
\end{abstract}

Keywords Co-production $\cdot$ Sustainability science $\cdot$ Power relations $\cdot$ IPBES $\cdot$ Science and technology studies

\section{Introduction}

The involvement of diverse disciplinary and societal actors in knowledge-action systems is increasingly recognised as a necessary condition for the conduct of equitable, relevant, and usable sustainability research (Clark and Dickson 2003, Armitage et al. 2011, Cornell et al. 2013, Mauser et al. 2013, Clark et al. 2016). Such approaches have been

Handled by: Suneetha Subramanian, United Nations University Center Administration, India.

Electronic supplementary material The online version of this article (https://doi.org/10.1007/s11625-019-00669-w) contains supplementary material, which is available to authorized users.

Jasper Montana

jasper.montana@cantab.net

1 Department of Politics, University of Sheffield, Northumberland Road, Sheffield S10 2TU, UK

2 Department of Geography, University of Cambridge, Cambridge CB2 3EN, UK brought together under the rubric of 'co-production'- the philosophy and practice of recognising the interdependencies between knowledge and the social systems in which it is produced and used. Co-production is now a guiding principle for a wide range of regional and global sustainability research programmes (such as Future Earth; van der Hel 2016). Until recently, the practice of co-production has been treated as a research ideal rather than a clearly defined set of principles and methods (Beier et al. 2017). However, a growing body of scholarship suggests that there is much to learn from experience in shaping both the theory and practice of co-production (Pohl et al. 2010, Schuttenberg and Guth 2015, Wyborn 2015a, 2015b, Beier et al. 2017, Miller and Wyborn 2018). In particular, there is an opportunity to further develop the analytical resources that can explicitly recognise and account for the power relations in co-production initiatives.

The significance of the relationship between knowledge and power has been previously emphasised. Theoretical developments in science and technology studies have suggested that knowledge itself is infused with the values of 
those that produce it (see notable examples in Keller 1985, Haraway 1989, Jasanoff 2004). From this perspective, the production of knowledge has a function in representing a particular set of interests by controlling the resources that societies have available to know and act in the world. In work on sustainability, this means that even simple choices about what kinds of knowledge to produce may be perceived by some as taking sides in debates by prioritising one set of interests over others (Clark et al. 2016). Recognising the inherent power dynamics within knowledge-action systems has been a key driver for developing the practice of co-production through which scholars and stakeholders collaborate in defining the scope and conduct of knowledge production (Miller and Wyborn 2018). However, the operationalisation of co-production in this way is not without contention. Attempts to establish design principles for co-production have been criticised for obscuring the power differentials that the practice of co-production is intended to rebalance (Goldman et al. 2018). The development of additional analytical resources for perceiving power dynamics can therefore help to promote more theoretically informed attempts to design and analyse co-production initiatives for sustainability.

Focusing on co-production in action, this paper deploys social theory from science and technology studies to develop an approach to recognise power relations between the participants, processes, and products. In doing so, the article emphasises the need to be attentive to the organisational dimensions of the multiple and distributed organisational spaces where co-production takes place, and trace the power relations within and between them. Finally, the paper applies this perspective to consider the organisational dimensions of co-production in an illustrative case study of a current international sustainability initiative: the Intergovernmental Platform on Biodiversity and Ecosystem Services (IPBES). This global expert process was initiated in 2012 to strengthen science and policy for biodiversity at the international level. The case of IPBES offers valuable insight into the challenges and opportunities for designing and evaluating co-production initiatives more broadly.

\section{Organisational dimensions}

A major challenge of recognising power relations in co-production is considering where within a programme or initiative co-production is seen to take place. One simple response to this challenge is to assume that co-production takes place where it is intentionally designed. In these terms, the practice of co-production refers to specific attempts to curate the co-productive interactions of participants within processes in particular times and places. If a research programme involves a single stakeholder workshop, then co-production might be perceived at the scale of the workshop. Alternatively, if a research programme has embedded co-production throughout, then co-production might be perceived at the scale of the whole research programme. While this perspective can provide a coarse guide for locating and refining the practice of co-production, it offers undue privilege to the view of the designers of these initiatives and fails to recognise the agency of individuals to govern their own engagement with a process. This perspective also unproductively isolates a co-production initiative from what comes before and after, as well as the wider social settings in which it is carried out.

If the practice of co-production is to draw lessons from the existing literature on the relationship between knowledge and power, then co-productive interactions should be considered to be inevitable and ubiquitous outcomes of social life that extend beyond specific initiatives (Miller and Wyborn 2018). In other words, the dynamic co-emergence of knowledge with social relations happens by design or otherwise, and concurrently at multiple scales. From this perspective, co-production permeates throughout and beyond the boundaries of any curated activities, making the organisational scales of co-production difficult to discern.

The case of IPBES developed in this paper offers a clear illustration of this challenge. Like many organisations operating at the science-policy interface (Pallett and Chilvers 2015), the IPBES process lacks precise organisational boundaries. The vast majority of contributors are involved only on a temporary and transient basis through specific tasks and roles, and generally hold permanent employment in other organisations. The expert process is also subject to the external influences of publishing trends, the changing funding landscape, and the continuing support of external partners to help deliver its work. This creates a methodological and conceptual challenge of making sense of the organisational design of the many structures of IPBES, from author meetings to intergovernmental negotiations, and how they interconnect to give form to the IPBES process. This paper argues that perceiving co-production in action therefore requires detailed attention to the human scale of participatory interactions that take place in particular times and places.

The analytical lens developed in this paper describes these situated participatory interactions as co-productive forums-defined as socially constituted organisational spaces positioned in time and space where interactions are facilitated through structured, but continuously negotiated relations between participants, processes and products. From a collaborative workshop to an online email exchange, and from an interview to a lunch meeting, co-productive forums are observable interactions where participants interact in a process that produces products. In the normal conduct of science for sustainability, participants might be researchers, 
stakeholders, or policy makers; the process might be a workshop or collaboration; and the products might be common scientific outputs, such as papers and reports, but may also include new social networks, collective agendas, or other outcomes (see Miller and Wyborn 2018).

The lens of co-productive forums draws attention to the organisational dimensions that define these interactions. It is typical, for example, for co-productive forums to have a framework of participation, which allows the involvement of some individuals and not others. Similarly, co-productive forums frequently have frameworks of representation, whereby individuals are chosen to participate as designated representatives of external communities or particular world views. Co-productive forums also operate through implicit or explicit frameworks of deliberation, which determine how interactions will take place and decisions will be made. Finally, co-productive forums tend to result in outcomes that are carried forward into subsequent activities through a framework of circulation. As well as providing a practical analytical lens for thinking about the design and evaluation of co-production initiatives, these concepts also have a wealth of theoretical development that can be brought into the further theorisation of the practice of co-production for sustainability.

Drawing on the language of political science, the concepts of participation, representation and deliberation derive from scholarship on different models of democracy (Held 2006; Lidskog and Elander 2007). Each of these concepts have a long history of development in both scholarly and practical use reflecting both analytical terms and ideal types for considering democratic organisation. Scholarship on participatory democracy, for example, has developed around the role of citizens as direct participants in decision-making processes (see, for example, Pateman 1970, Pateman 2012). The model of representative democracy reflects an arrangement whereby elected officials are authorised to make decisions on behalf of a wider population (see, for example, Pitkin 1972, Urbinati 2006). Finally, the deliberative model of democracy, by contrast, is sometimes seen as a hybrid model in which those subject to collective decisions either participate or are represented in the authentic, inclusive and consequential dialogue that informs those decisions (see, for example, Dryzek 2007, Dryzek 2012). These different perspectives sometimes engender tensions amongst scholars around the functioning and purpose of democracy, but elements of these democratic models can be seen as operating in concert with one another in different political systems.

These democratic concepts have also been applied in the field of science and technology studies. The idiom of co-production (Jasanoff 2004), which is distinct from, but highly relevant to, the practices of co-production for sustainability, has drawn parallels between knowledge production and democratic politics as models of social organisation.
Here, the democratic concepts of participation, representation and deliberation have been applied as a comparative framework to understand the ways in which historical and cultural norms shape the production, validation and use of knowledge in different national political systems (Jasanoff 2005), and have also been recognised as important to the politics of knowledge in IPBES (Montana 2017). Following this tradition, these concepts are applied in this paper to consider the organisational dimensions of co-productive forums. However, while this tripartite framework can effectively describe the organisational structure of a single co-productive activity, such as a workshop or committee meeting, it does not yet take account of how one co-productive forum might interact with another. The analytical lens developed in this paper, therefore, makes the addition of circulation as an important organisational dimension. The concept of circulation has an established scholarly foundation, examined in analyses on the mobility of people, documents and social norms in the structure of social systems (see, for example, Anderson 1983, Latour 1990, Mitchell 2002). Applied in this paper, the concept of circulation helps to trace the connections between the organisational spaces of co-production in relation to each other across time and space.

Drawn together, the concepts of participation, representation, deliberation and circulation provide a set of axes through which to unpack the power relations between participants, processes and products in the practice of coproduction. Participation considers the relationship between participants and the process; representation considers the relationship between participants and those outside of the process; deliberation considers the relations between the participants themselves and the outcomes that they produce; and circulation considers the relationship between participants, processes and products of one co-productive forum with those of another (Fig. 1). Examined in context, these organisational dimensions can tease apart the power dynamics in the practices of co-production. Indeed, they offer a comparative lens through which to consider how organisational spaces are structured and how the structure distributes power relations between those involved. In bringing the dimensions of co-productive forums to light, the case study of IPBES as a current international sustainability initiative offers some further insights about how these dimensions can enrich our understanding of co-production, and develops lessons for its design and evaluation.

\section{Co-production in IPBES}

The IPBES process was formally initiated through the United Nations system to strengthen the science and policy of biodiversity and ecosystem services at the international level. The Platform was partially modelled on the 

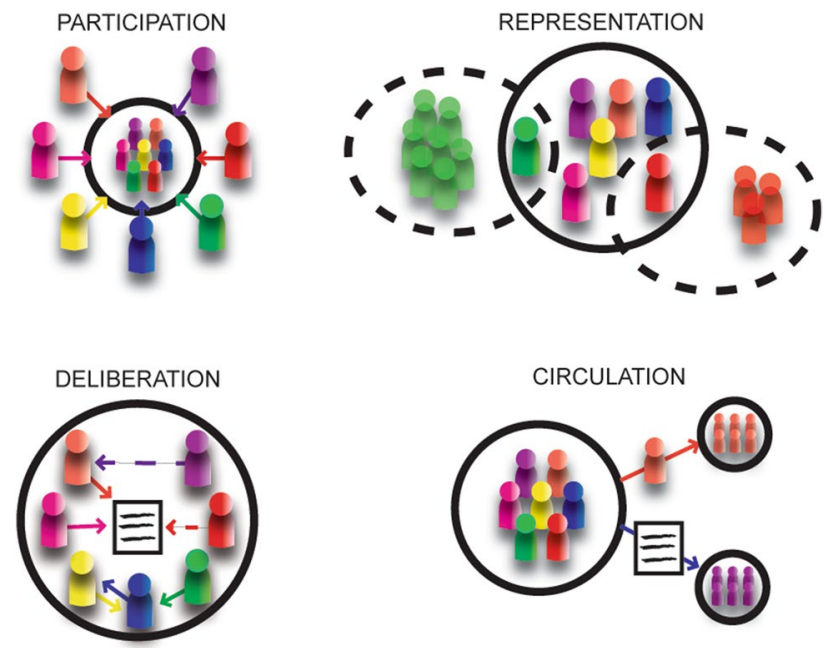

Fig. 1 The organisational dimensions of co-productive forums: participation, representation, deliberation and circulation

long-standing Intergovernmental Panel on Climate Change (IPCC) and has therefore established an intergovernmental structure with current membership of around 130 national governments and over 1000 experts that have contributed to its first work programme (2014-2018). However, the IPBES process has a broader mandate to not only produce scientific assessments on the state of knowledge, but also build capacity and support the development of science and policy for biodiversity internationally. The platform has ambitious operating principles, which include a commitment to open up participation to a wider range of experts and knowledge systems, including indigenous and local knowledge (IPBES 2012, Díaz et al. 2015). The diverse participants in the work of IPBES have already contributed to the development of new conceptual approaches to understanding the relationship between people and nature (Borie and Hulme 2015; Díaz et al. 2018), evidencing the Platform's contributions as a co-production initiative.

In this paper, the IPBES process is developed as a case study to illustrate the application of co-productive forums as an analytical lens for examining organisational dimensions in co-production initiatives. The IPBES process also offers an example of co-production in action from which to derive lessons for designers and analysts of future coproduction activities. The IPBES process is a valuable case study of co-production because its work has been both open to scholarly observation and is well-documented. According to UN tradition, the negotiations that have defined the formal structures, functions and processes of IPBES have been conducted in the presence of observers and have been carefully documented in meeting reports and the published scholarly literature (Granjou et al. 2013; Vadrot 2014). This sets the IPBES process apart from many co-production initiatives, which might conduct planning meetings in private and fail to record the history of their decisions. The organisation of IPBES can thus be observed and analysed at a level of granularity that is rarely reported for many co-production initiatives. Although IPBES represents a particular kind of 'global' initiative, the analytical lens developed in this paper seeks to highlight that the organisational dimensions of the IPBES process still take place at the level of human interactions. Lessons from this case therefore have relevance for other cases of co-production in action.

The qualitative research on IPBES that underpins this brief analysis was carried out between 2013 and 2016. This research included 19 semi-structured interviews with five administrators and fourteen participating experts selectively sampled from the IPBES process. Additional data were collected through participant observation at three intergovernmental plenary meetings (Antalya, Turkey in 2013; Bonn, Germany in 2015; and Kuala Lumpur, Malaysia in 2016); an author group meeting (March 2015); a joint meeting of IPBES task forces (April 2015); meetings of the two subsidiary bodies (April 2015); as well as during a 4-month placement with the IPBES secretariat based in Bonn, Germany (January-April 2015). The data were analysed through a three-pass coding process in qualitative analysis software following a grounded-theory approach, by which frameworks of analysis were defined in parallel with data collection and analysis (as per Charmaz 2006). The research was conducted under ethical approval from the Department of Geography at the University of Cambridge (Approved: 23rd July 2014). This empirical research provided in-depth understanding of the IPBES process as an important interpretive context for examining co-production in action, and is contextualised below in relation to the growing body of published literature and official documents from the IPBES process.

The case of IPBES highlights that co-production in action presents a challenge for designers and analysts, alike. The IPBES process has been comprised of numerous group encounters taking place across the intergovernmental plenary, the technical and administrative bodies, and the author groups of the Platform. Many of the organisational dimensions of these formal co-productive forums are defined in the IPBES rules of procedure that include specific rules about who should participate, who and what should be represented, and how decisions should be made. However, the IPBES process has also been comprised on many informal co-productive forums that were not envisaged from the outset, but rather emerged in the interstices of IPBES meetings over lunch and coffee breaks where individuals from across the various structures gathered to discuss arising issues. The co-productive forums of IPBES are therefore characterised by time-bound and often task-specific interactions, which have collectively brought the diverse participants of IPBES into a structured network of organisational spaces to carry 
out the Platform's mandated activities. A brief analysis of the organisational dimensions of IPBES highlights some important considerations for perceiving power relations in co-production initiatives.

\section{Participation in IPBES}

In IPBES, participants predominantly came together in formal meetings. These meetings included, for example, the annual plenary meetings that brought together government delegates, and author group meetings that brought together experts from around the world. For many of these forums, frameworks of participation that determined what processes would take place and how participants would relate to those processes have been set out in the Platform's rules of procedure [SM1.1]. Perhaps the most regulated co-productive forum was the intergovernmental Plenary, where participation has been limited to government members of IPBES and a small number of sanctioned non-governmental stakeholders, including experts from the IPBES process. Observers at plenary meetings have been allowed to attend, but unlike governments, they have not had vetoing or voting rights, and have only been allowed to speak when invited by government delegates. However, the case of IPBES illustrates how frameworks of participation are subject to interpretation and change over time. Reflecting on the participation of the IPBES Multidisciplinary Expert Panel in the Platform's plenary meetings, one of its members commented in February 2015:

"the Plenary in many ways, it functions a lot like the [Convention on Biological Diversity], or all these other [inter]governmental things. Scientists just have a really hard time getting into that. And, if you look at the history of IPBES, [the Multidisciplinary Expert Panel] were begrudgingly given more and more space to participate in Plenaries. The first plenary, the [Multidisciplinary Expert Panel] was not invited until the last minute and when we were, we were kind of stuck off in a little corner, and we still don't have microphones at our desks, for example. It's changed a bit, because [at the plenary meeting in January 2015] we were up on the podium relatively frequently to provide input on the different deliverables. And that's new."

Beyond the stipulated text in the rules of procedure, the terms of participation in the IPBES plenary meetings have therefore been a point of negotiation as the IPBES process has evolved to facilitate more comprehensive dialogue between participating experts and government delegates.

The process of defining participation is perhaps one of the most concentrated sites of power in a co-production initiative. Previous scholarship has shown that while the concept of participation is generally applied to consider the process of inclusion, it inevitably also involves a process of exclusion (Turnhout et al. 2010, Ragnhild et al. 2015). In deciding on who participates, designers of co-production initiatives also make decisions about who does not participate (Arnstein 1969, Shirk et al. 2012). Such decision may be explicitly determined through the creation of a participant list, but can also be implicitly determined through more mundane and seemingly benign considerations, such as the provision of microphones to participants. Similarly, decisions about the timing and location of a meeting, the size of a room, the proposed topic of discussion, the perceived scope of an issue, and the purpose of participatory engagement all contribute to constructing the framework within which participation takes place (Turnhout et al. 2010). However, the power to define participation does not lie solely with the designers of co-production initiatives. Potential participants and their access to the resources that facilitate participation can also influence relations to a co-production process. In IPBES, the question of who participated did not only depend on the written rules of procedure and the distribution of an invitation to participate, but also relied upon the active engagement of potential participants themselves to seek selection for the process and to have the financial support, time and capacity to participate in the meetings (Kovács and Pataki 2016). In this regard, participation as an organisational dimension might be better understood to follow 'rules in use' rather than 'rules on paper' (citing the distinction set out in Young 2002), whereby it becomes an evolving outcome of co-production initiatives. While designers may be able to set the formal boundaries of a co-productive forum, potential participants retain the power to choose the way in which they relate to the process.

\section{Representation in IPBES}

The IPBES process has invested heavily in ensuring diverse representation in the expert groups of the Platform. In seeking inclusivity, the IPBES process has developed frameworks of representation that divide up participants according to a system of classification that support the monitoring of diversity in IPBES. One representative category that has received particular attention has been the regional diversity of the expert groups, which an IPBES administrator explained in June 2015 has been intended to appeal to both the political and epistemic communities that IPBES wants to represent in its work.

"The regional representativeness has very much to do, obviously, on one angle with the representation of nations in the system as it is an intergovernmental set up, and we live in a world where national representation is still one of the main ways of political form of expression at the international level. [...] But 
obviously, with that, regional representation becomes clearly also one which not only speaks to legitimacy, but also to relevance and credibility. You know the issue of biodiversity is clearly a very different one depending if you are in one region or another region."

For IPBES, frameworks of representation have provided one way in which to establish its authority (described by this administrator as legitimacy, relevance and credibility, following the framework set out in Cash et al. 2003). To further legitimise the experts of the process, an emphasis has been placed on the process through which these experts have been authorised to participate. Selected experts have been nominated by governments or relevant stakeholders, and formally selected by the Multidisciplinary Expert Panel [SM1.2], signifying their authorisation as relevant experts. However, despite the significance placed in frameworks of representation in the selection and monitoring process in IPBES, the organisational dimension of representation is also downplayed at times in the IPBES process. Experts participating in the Multidisciplinary Expert Panel, for example, may be selected based on their nomination by particular regional governments, but they are expected to relinquish any regional representation and act in their own personal capacity when contributing to the IPBES process [SM1.3].

For the most part, frameworks of representation in the IPBES process have functioned as valuable heuristics for monitoring diversity in the Platforms work. The balance of experts from different genders, regions and knowledge systems in the IPBES expert groups has been able to be monitored and reported throughout the first work programme (Montana and Borie 2016, Montana 2017, Timpte et al. 2018). However, frameworks of representation also function as sites for the enactment of power. The act of creating systems of classification that are applied to human subjects can create power imbalances in the social structures of communities (Bowker and Star 2000) and this can make systems of classification contested. In the case of IPBES, for example, indigenous representatives present at Plenary meetings consistently rejected the label of 'stakeholder' under which they were being considered by the formal rules of procedure. Instead, representatives at an IPBES plenary meeting in 2013 asserted the position of indigenous peoples as "knowledge-holders, rights-holders, and partners" of the IPBES process (Carino 2013, cited in Esguerra et al. 2017). This tension around an appropriate categorisation of indigenous peoples present in plenary meetings was partially resolved by the establishment of a self-defined collective-the International Indigenous Forum on Biodiversity and Ecosystem Services-that could act as a stakeholder to the Platform, rather than indigenous peoples themselves being a designated group in the stakeholder community [SM1.4]. This example highlights that participants bring multiple perspectives, commitments, responsibilities and agendas into co-production processes (O'Neill 2001) and often demand the right of self definition. For co-production initiatives, this means that broad classificatory groupings, such as 'stakeholders', 'knowledge brokers', 'indigenous peoples', and 'policy makers', which may offer useful heuristics for designing co-production activities, can have divergent interpretations concerning who can legitimately represent these identities in any given activity (Turnhout et al. 2010). While systems of classification in co-production initiatives help designers and analysts to take account of diversity, the identities that these classifications ascribe to participants are likely to remain open to challenge.

\section{Deliberation in IPBES}

In IPBES, frameworks of deliberation, by which participants contributed their perspectives, discussed and debated them, and fed them into the outcomes of the Platform's work, varied dramatically across the different co-productive forums. The intergovernmental plenary, for example, had the most formal framework of deliberation, which followed the United Nations tradition for intergovernmental negotiations (broadly following UNEP 2007). This tradition has resulted in plenary meetings taking place in large halls, where government delegates are given the opportunity to make formal statements to the meeting. However, plenary meetings also provided opportunities for informal forums to be temporarily established amongst their participants. One notable example is the informal co-productive forum that has often been established at the podium in IPBES plenary meetings (Fig. 2). The podium has typically taken the form of a raised table at the front of the plenary meetings where the Chair of the session, members of the IPBES secretariat, and members of the IPBES subsidiary bodies or other experts have typically sat to oversee proceedings. While this group participates in the main intergovernmental forum, at times they also break away into an informal forum to discuss organisational issues and create a strategy about the best way to carry the negotiations forward. In general, outside of the intergovernmental plenary, co-productive forums have much looser frameworks of deliberation. For example, there has been no explicit tradition by which the experts in the process have been intended to deliberate, but there has been expectations set out in the rules of procedure concerning the processes and timelines for deliverables, and some guidance has been provided by the IPBES administrators that oversee the Platform's work. One of the experts allocated to the Methodological Assessment on biodiversity models and scenarios, for example, explained the deliberative approach of their author groups in June 2015. 


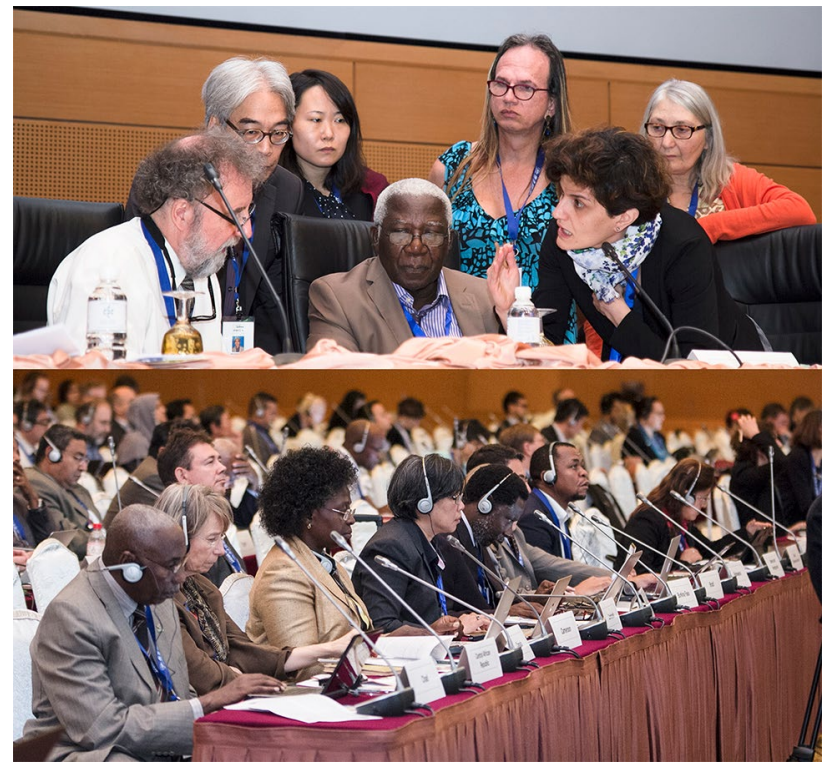

Fig. 2 The 'podium' situated at the front of IPBES intergovernmental plenary meetings (top image) was an organisational space that developed an informal framework of deliberation where the Chair of the session, IPBES administrators, and other invited experts could converse. This was in contrast to the intergovernmental Plenary (bottom image) that had a formal framework of deliberation following a United Nations tradition of negotiation and consensus-based decision-making mediated through microphones. Shown here during the Plenary meeting of IPBES in Kuala Lumpur, Malaysia in 2016 (Photo by IISD/Sean Wu: enb.iisd.org/ipbes/ipbes4/26feb.html; enb.iisd.org/ ipbes/ipbes $4 / 25$ feb.html)

"A process like this brings together a group of individuals-almost 80 individuals in our case-who have all been nominated by their governments or a by a stakeholder group. So people from all over the world, all sorts of different backgrounds, different world views and so on. And yeah! It is a real challenge working together trying to produce something like this. And to be very frank. I have had [Coordinating Lead Authors] come to me, particularly early in the process, and basically say this whole thing would be ten times easier if it was just six of us writing this thing. And we would've had it finished in a few weeks rather than it taking almost 18 months. But of course that misses the whole point, which is if the document was written in that way, then it simply would not have ownership by the members of IPBES. So, we've really got to go through what at times feels like a very torturous process to end up with something that will hopefully be owned by the IPBES plenary."

Despite there being no stringent guidelines in IPBES about how expert groups should structure their interactions, the organisation of the IPBES process in which large groups of authors have to collaborate according to a fixed timeline of iterative drafting and review has started to establish a framework of deliberation directed towards collaboration despite difference, as well as joint ownership across its activities.

As demonstrated in IPBES, frameworks of deliberation are typically difficult to prescribe from the outset, and tend to emerge depending on the participants and the process that they are involved in (van den Hove 2006). Yet, frameworks of deliberation are key organisational dimensions, defining the way in which participants relate to one another and the outcomes that are produced (Bellamy et al. 2017). They can therefore act as a hidden reservoir of power for some participants. In international processes in particular, being attentive to cultural difference is particularly important. While some approaches to debate and decision making may seem perfectly natural to one group of participants, these frameworks of deliberation can unintentionally alienate another (Jasanoff and Martello 2004). It should also be noted that while the establishment of informal forums, such as that found on the podium at IPBES plenary meetings, can be particularly useful in co-production initiatives to temporarily break away from formal deliberations, these informal forums can also create organisational spaces that subvert frameworks of deliberation in a way that can implicitly or explicitly exclude some participants.

\section{Circulation in IPBES}

In IPBES, connections between co-productive forums were made by things that were mobile, such as experts who attended multiple meetings or the rules and reports that also travel from one meeting to the next. In some cases, these circulations were strategically designed into the IPBES work programme. For example, IPBES administrators sought to link some expert groups with other expert groups to share information between them. To this end, they saw an opportunity in having some experts working on one assessment, also working on another. As one of the IPBES administrator explained in May 2015:

"if you look at one assessment as one network, if you want to couple it, it is important to have some people from that network being in the other network and then that information very quickly flows into the new networks."

This strategy was considered particularly useful for linking up the work of the various assessment reports, such as the regional and thematic assessments, that were being produced in parallel during the first work programme [SM1.5]. By having experts across multiple assessment reports, the distinct forums could respond to and influence the 
expectations, needs and commitments of the other activities. In addition, circulation in IPBES took place with the passage of documents through the various forums of the Platform. An assessment report would begin its life as a scoping document that would pass from the intergovernmental plenary, into an expert group, through three rounds of expert and government review, before returning to the plenary for final approval [SM1.6]. Each co-productive forum had slightly different authority to make changes to the assessment report with the intergovernmental plenary giving final sign off to its contents. Tracing circulating people and documents within the IPBES process can therefore reveal the relative power balances between different forums.

Frameworks of circulation recognise that co-productive forums do not exist in isolation, but are instead situated in space and time, and therefore connected to the events that come before and after, as well as the wider social settings in which they operate. In IPBES, circulations, such as the rules of procedure, the assessment reports, and the experts themselves were fundamental to the working of the Platform. They provided opportunities to share information, carry forward mandates, translate rules set by the intergovernmental plenary to the other working groups of the Platform, and to build collective ownership of assessment reports without the need for direct interactions between experts, governments and reviewers. Circulations of people and documents have been recognised as fundamental to the working of science more generally (Latour 1987: 215-257), and previous research has called for attention to the way that these circulations change their form, function, and reception as they travel between different places (Latour 1999, Berger and Esguerra 2018). There are therefore implications for examining power in co-production initiatives that can be explored through questioning what outcomes of co-production circulate, who or what carries them, and the reception they receive when introduced into another co-productive forum. As in IPBES, whether or not products from one forum are well received, ignored or rejected by another may depend on the relationship of authority between the different forums.

\section{Conclusion}

The account of IPBES offered in this paper is of an organisation not defined by clear organisational boundaries, but rather a network of multiple and distributed co-productive forums connected through linked agendas and tethered response systems, which have provided a loose structure for the Platform's work. This analysis is achieved by paying attention to the organisational dimensions through which co-production is organised and offers lessons that can inform other attempts to design and study co-production initiatives.
Most significantly, the networked view of co-productive forums illustrated by the case of IPBES highlights that organisational dimensions that define the practices of coproduction cut across both formal and informal interactions from the beginning to end of a co-production initiative. Seeing the networked structure of co-production initiatives through the concept of circulation ensures that co-production is seen as an activity that is situated in space and time, and always with respect to other social processes. The planning and design of a co-productive activity, as has taken place in the intergovernmental negotiations setting out the rules of procedure of the IPBES process, is itself a site of co-production. Attention can therefore be directed to the ways in which these forums of design are themselves constructed through organisational dimensions, which may or may not uphold the intended values of a co-production process. The IPBES case also clearly highlights the prevalence of emergent and selforganised informal forums, which can easily be discounted from co-production design. It is significant to note that these too are important organisational spaces in which power is enacted and relations are made. Indeed, this analysis of the case of IPBES suggests that even formal forums with seemingly rigid organisational dimensions are open to negotiation in practice. The extent to which the structures, functions and processes have been debated in IPBES highlights that the design of organisational dimensions is infused with human values about how social relations should be organised, and who or what should be accounted for in the process. The experience of IPBES therefore supports the assertion that co-production goes far beyond simply integrating diverse perspectives and securing joint ownership of knowledge. Rather, it emphasises co-production as a process of learning from and adapting to different ways of organising social relations. Finally, the analysis of IPBES suggests that co-production design and analysis requires a thorough understanding of how social norms, which may be invisible to some participants, can influence the power differentials between those engaged in deliberation. Responding to this challenge will require designers of co-production initiatives to be more explicit about how adopted organisational frameworks take account of cultural differences between the participants. The purposeful consideration of power relations in co-production initiatives can help further this aim.

While any particular lens on the power dynamics of knowledge production will be unavoidably partial, the framework developed in this paper contributes to a body of analytical resources that can contribute to thinking about the power differentials in the practice of co-production. The concept of organisational dimensions developed in this paper places the democratic concepts of representation, participation and deliberation that have long underpinned the desire to broaden the power base of knowledge-action systems at the centre of the analysis, and 
situates these in a networked structure through the concept of circulation. By connecting work on co-production for sustainability to existing scholarship from science and technology studies and democratic theory, it is hoped that this framework can further open up opportunities for a more theoretically and practically informed approach to designing and analysing co-production. This analytical lens, for example, offers a general framework that could be applied in comparative and experimental research. The identified organisational dimensions could be applied to a growing body of scholarship on multi-sited ethnography to examine large-scale meetings and distributed events (Campbell et al. 2014) as a means of tracing the power relations within and between these organisational spaces. Alternatively, analysing the effects of different organisational dimensions could be examined in experimental work (Bellamy et al. 2017) on the effects of prescribed organisational dimensions on the outcomes of co-production activities. Furthermore, while often focused on human participants, the examination of organisational dimensions might equally be developed into analyses that take into account non-human actors in the practice of co-production (Latour 2004). These could explore, for example, the way that microphones, computers, aeroplanes and clocks participate in or shape the design of co-productive forums, and the subsequent implications this can have on power differentials in these processes.

There is a significant challenge that persists for designers of co-production initiatives. The practice of co-production is becoming increasingly prominent and there are high expectations about its potential to broaden the power base of knowledge-action systems. However, the practice of coproduction is constrained by the realities of research and governance for sustainability. Designers of co-production activities are required to work with resource limitations as they balance the uncertainty associated with any evolving co-productive process with demands for efficiency and effectiveness. In navigating this challenge, this article emphasises that there is value in exploring new approaches to conceptualise the organisation of co-production by drawing on insights from existing theory and practice. By examining co-productive forums in the case of IPBES, this article calls for a greater engagement with organisational dimensions as both important mechanisms through which the practice of co-production opens up knowledge-action systems to more diverse participants, but also as frameworks through which the changes in social relations and redistributions of power in co-production initiatives can be more effectively evaluated.

Acknowledgements This work was supported by the Economic and Social Research Council [grant number 1362673]. The author would like to thank experts and administrators of the Intergovernmental
Platform on Biodiversity and Ecosystem Services for their time and advice during data collection. Gratitude is also due to Bill Adams and James Wilsdon for comments and guidance on earlier versions of this work.

Open Access This article is distributed under the terms of the Creative Commons Attribution 4.0 International License (http://creativeco mmons.org/licenses/by/4.0/), which permits unrestricted use, distribution, and reproduction in any medium, provided you give appropriate credit to the original author(s) and the source, provide a link to the Creative Commons license, and indicate if changes were made.

\section{References}

Anderson B (1983) Imagined Communities: reflection on the origins and spread of nationalism. Verso, London

Armitage D, Berkes F, Dale A, Kocho-Schellenberg E, Patton E (2011) Co-management and the co-production of knowledge: learning to adapt in Canada's arctic. Global Environ Change 21(3):995-1004. https://doi.org/10.1016/j.gloenvcha.2011.04.006

Arnstein SR (1969) A ladder of citizen participation. J Am Plan Assoc 35(4):216-224. https://doi.org/10.1080/01944366908977225

Beier P, Hansen LJ, Helbrecht L, Behar D (2017) A how-to guide for coproduction of actionable science. Conserv Lett 10:288-296. https://doi.org/10.1111/conl.12300

Bellamy R, Lezaun J, Palmer J (2017) Public perceptions of geoengineering research governance: an experimental deliberative approach. Global Environ Change 45:194-202. https://doi. org/10.1016/j.gloenvcha.2017.06.004

Berger T, Esguerra A (2018) Introduction. In: Berger T, Esguerra A (eds) World politics in translation: power, relationality and difference in global cooperation. Routledge, London, pp 1-21

Borie M, Hulme M (2015) Framing global biodiversity: IPBES between mother earth and ecosystem services. Environ Sci Policy 54:487-496. https://doi.org/10.1016/j.envsci.2015.05.009

Bowker GC, Star SL (2000) Sorting things out: classification and its consequences. MIT Press, Cambridge, MA

Campbell LM, Corson C, Gray NJ, MacDonald KI, Brosius JP (2014) Studying global environmental meetings to understand global environmental governance: collaborative event ethnography at the tenth conference of the parties to the convention on biological diversity. Global Environ Politics 14(3):1-20. https://doi. org/10.1162/GLEP_e_00236

Carino J (2013) Statement delivered on behalf of the International Indigenous Forum on Biodiversity and Ecosystem Services at IPBES-2, Antalya, Turkey, December 9-14

Cash DW, Clark WC, Alcock F, Dickson NM, Eckley N, Guston DH, Jäger J, Mitchell RB (2003) Knowledge systems for sustainable development. Proc Natl Acad Sci 100(14):8086-8091. https://doi. org/10.1073/pnas.1231332100

Charmaz K (2006) Constructing grounded theory: a practical guide through qualitative analysis. Sage, London

Clark WC, van Kerkhoff L, Lebel L, Gallopin GC (2016) Crafting usable knowledge for sustainable development. Proc Natl Acad Sci 113(17):4570-4578. https://doi.org/10.1073/pnas.1601266113

Clark WC, Dickson NM (2003) Sustainability science: the emerging research program. Proc Natl Acad Sci 100(14):8059-8061. https ://doi.org/10.1073/pnas.1231333100

Cornell S, Berkhout F, Tuinstra W, Tàbara JD, Jäger J, Chabay I, de Wit B, Langlais R, Mills D, Moll P, Otto IM, Petersen A, Pohl C, van Kerkhoff L (2013) Opening up knowledge systems for better responses to global environmental change. Environ Sci Policy 28:60-70. https://doi.org/10.1016/j.envsci.2012.11.008 
Díaz S, Demissew S, Joly C, Lonsdale WM and Larigauderie A (2015) A rosetta stone for nature's benefits to people. PLoS Biol 13(1):18. https://doi.org/10.1371/journal.pbio.1002040

Díaz S, Pascual U, Stenseke M, Martín-López B, Watson RT, Molnár Z, Hill R, Chan KMA, Baste IA, Brauman KA, Polasky S, Church A, Lonsdale M, Larigauderie A, Leadley PW, van Oudenhoven APE, van der Plaat F, Schröter M, Lavorel S, Aumeeruddy-Thomas Y, Bukvareva E, Davies K, Demissew S, Erpul G, Failler P, Guerra CA, Hewitt CL, Keune H, Lindley S, Shirayama Y (2018) Assessing nature's contributions to people. Science 359(6373):270. https ://doi.org/10.1126/science.aap8826

Dryzek JS (2007) Theory, evidence and the tasks of deliberation. In: Rosenberg SW (ed) Deliberation, participation and democracy: can the people govern?, Palgrave Macmillan, London, pp 237-250

Dryzek JS (2012) Foundations and frontiers of deliberative governance. Oxford University Press, Oxford

Esguerra A, Beck S, Lidskog R (2017) Stakeholder engagement in the making: IPBES legitimization politics. Global Environ Politics 17(1):59-76. https://doi.org/10.1162/GLEP_a_00390

Goldman MJ, Turner MD, Daly M (2018) A critical political ecology of human dimensions of climate change: epistemology, ontology, and ethics. WIREs Climare Change 9(e526):1-15. https://doi. org/10.1002/wcc. 526

Granjou C, Mauz I, Louvel S, Tournay V (2013) Assessing nature? The genesis of the intergovernmental platform on biodiversity and ecosystem services (IPBES). Sci Technol Soc 18(9):9-27. https:// doi.org/10.1177/0971721813484232

Haraway D (1989) Primate Visions: Gender, race, and nature in the world of Modern Science. Routledge, New York

Held D (2006) Models of democracy, 3rd edn. Polity, Cambridge, Malden, MA

IPBES (2012) Functions, operating principles and institutional arrangements of the Intergovernmental science-policy platform on biodiversity and ecosystem services. IPBES, Bonn

Jasanoff S (ed) (2004) States of Knowledge: the co-production of science and social order. Routledge, London

Jasanoff S (2005) Designs on nature: science and democracy in Europe and the United States. Princeton University Press, Princeton, NJ, Oxford

Jasanoff S, Martello ML (2004) Knowledge and governance. In: Jasanoff S, Martello ML (eds) Earthly politics: local and global in environmental governance. MIT Press, Cambridge, MA, pp $335-350$

Keller EF (1985) Reflections on gender in science. Yale University Press, New Haven, CT

Kovács EK, Pataki G (2016) The participation of experts and knowledges in the Intergovernmental Platform on Biodiversity and Ecosystem Services (IPBES). Environ Sci Policy 57:131-139. https ://doi.org/10.1016/j.envsci.2015.12.007

Latour B (1987) Science in action: How to follow scientists and engineers through society. Open University Press, Milton Keynes

Latour B (1990) Drawing things together. In: Lynch M and Woolgar S (eds) Representation in scientific practice. MIT Press, Cambridge, MA., pp 19-68

Latour B (1999) Circulating reference. In: Latour B (ed) Pandora's hope: essays on the reality of science studies. Harvard University Press, Cambridge, MA. London, pp 24-79

Latour B (2004) Politics of nature: how to bring the sciences into democracy. Harvard University Press, Cambridge, MA

Lidskog R, Elander I (2007) Representation, participation or deliberation? Democratic responses to the environmental challenge. Space Polity 11(1):75-94. https://doi.org/10.1080/13562570701406634

Mauser W, Klepper G, Rice M, Schmalzbauer BS, Hackmann H, Leemans R, Moore H (2013) Transdisciplinary global change research: the co-creation of knowledge for sustainability. Curr
Opin Environ Sustain 5(3-4):420-431. https://doi.org/10.1016/j. cosust.2013.07.001

Miller CA, Wyborn C (2018) Co-production in global sustainability: histories and theories. Environ Sci Policy. 1-8. https://doi. org/10.1016/j.envsci.2018.01.016

Mitchell T (2002) Rule of experts: Egypt, techno-politics, modernity. University of California Press, Berkeley, CA, London

Montana J (2017) Accommodating consensus and diversity in environmental knowledge production: achieving closure through typologies in IPBES. Environ Sci Policy 68:20-27. https://doi. org/10.1016/j.envsci.2016.11.011

Montana J, Borie M (2016) IPBES and biodiversity expertise: Regional, gender and disciplinary balance in the composition of the interim and 2015 multidisciplinary expert panel. Conserv Lett 9(2):138-142. https://doi.org/10.1111/conl.12192

O'Neill J (2001) Representing people, representing nature, representing the world. Environ Plannin C 19(4):483-500. https://doi. org $/ 10.1068 / \mathrm{c} 12 \mathrm{~s}$

Pallett H, Chilvers J (2015) Organizations in the making: Learning and intervening at the science-policy interface. Prog Hum Geogr 39(2):146-166. https://doi.org/10.1177/0309132513518831

Pateman C (1970) Participation and democratic theory. Cambridge University Press, Cambridge

Pateman C (2012) Participatory democracy revisited. Perspect Politics 10(1):7-19. https://doi.org/10.1017/S1537592711004877

Pitkin HF (1972) The concept of representation. University of California Press, Berkeley, CA, London

Pohl C, Rist S, Zimmermann A, Fry P, Gurung GS, Schneider F, Speranza CI, Kiteme B, Boillat S, Serrano E, Hadorn GH, Wiesmann U (2010) Researchers' roles in knowledge co-production: experience from sustainability research in Kenya, Switzerland, Bolivia and Nepal. Sci Publ Policy 37(4):267-281. https://doi. org/10.3152/030234210X496628

Ragnhild L, Smita Mishra P, Manju Prava D (2015) Narrating spaces of inclusion and exclusion in research collaboration-researchergatekeeper dialogue. Qual Res 16(3):280-292. https://doi. org/10.1177/1468794115611208

Schuttenberg HZ, Guth HK (2015) Seeking our shared wisdom: a framework for understanding knowledge coproduction and coproductive capacities. Ecol Soc 20(1):15. https://doi.org/10.5751/ ES-07038-200115

Shirk JL, Ballard HL, Wilderman CC, Phillips T, Wiggins A, Jordan R, McCallie E, Minarchek M, Lewenstein BV, Krasny ME, Bonney R (2012) Public participation in scientific research: a framework for deliberate design. Ecol Soc 17(2):29. https://doi.org/10.5751/ ES-04705-170229

Timpte M, Montana J, Reuter K, Borie M, Apkes J (2018) Engaging diverse experts in a global environmental assessment: Participation in the first work programme of IPBES and opportunities for improvement. Innovation Eur J Soc Sci Res 31(sup1):S15-S37. https://doi.org/10.1080/13511610.2017.1383149

Turnhout E, Van Bommel S, Aarts N (2010) How participation creates citizens: participatory governance as performative practice. Ecol Soc 15(4):26

UNEP (2007) Multilateral environmental agreement: negotiator's handbook. Second Edition. University of Joensuu, Joensuu, Finland

Urbinati N (2006) Representative democracy: principles and genealogy. University of Chicago Press, London, Chicago

Vadrot ABM (2014) The politics of knowledge and global biodiversity. Routledge, London

van den Hove S (2006) Between consensus and compromise: acknowledging the negotiation dimension in participatory approaches. Land Use Policy 23(1):10-17. https://doi.org/10.1016/j.landu sepol.2004.09.001

van der Hel S (2016) New science for global sustainability? The institutionalisation of knowledge co-production in future earth. 
Environ Sci Policy 61:165-175. https://doi.org/10.1016/j.envsc i.2016.03.012

Wyborn C (2015a) Co-productive governance: a relational framework for adaptive governance. Global Environ Change 30:56-67. https ://doi.org/10.1016/j.gloenvcha.2014.10.009

Wyborn C (2015b) Connecting knowledge with action through coproductive capacities: adaptive governance and connectivity conservation. Ecol Soc 20(1):11. https://doi.org/10.5751/ES-06510 $-200111$
Young OR (2002) The institutional dimensions of environmental change: fit, interplay, and scale. MIT Press, Cambridge, MA, London

Publisher's Note Springer Nature remains neutral with regard to jurisdictional claims in published maps and institutional affiliations. 